\title{
Article \\ Analyzing the Scientific Evolution of the Sustainable Development Goals
}

\author{
Carmen Díaz-López (D), Cathaysa Martín-Blanco, Juan Jesús De la Torre Bayo, Benito Rubio-Rivera \\ and Montserrat Zamorano * $\mathbb{D}$
}

Citation: Díaz-López, C.;

Martín-Blanco, C.; De la Torre Bayo,

J.J.; Rubio-Rivera, B.; Zamorano, M.

Analyzing the Scientific Evolution of the Sustainable Development Goals. Appl. Sci. 2021, 11, 8286. https:// doi.org/10.3390/app11188286

Academic Editors: Marco Vona and Anming $\mathrm{Hu}$

Received: 4 August 2021

Accepted: 5 September 2021

Published: 7 September 2021

Publisher's Note: MDPI stays neutral with regard to jurisdictional claims in published maps and institutional affiliations.

Copyright: (c) 2021 by the authors. Licensee MDPI, Basel, Switzerland. This article is an open access article distributed under the terms and conditions of the Creative Commons Attribution (CC BY) license (https:/ / creativecommons.org/licenses/by/ $4.0 /)$.
Department of Civil Engineering, ETS Ingeniería de Caminos, Canales y Puertos, Campus Fuentenueva s/n, University of Granada, 18071 Granada, Spain; carmendiaz@ugr.es (C.D.-L.); cathaysamartin@ugr.es (C.M.-B.); juanjebdm@ugr.es (J.J.D.1.T.B.); brubio@ugr.es (B.R.-R.)

* Correspondence: zamorano@ugr.es

\begin{abstract}
Development must balance social, economic, and environmental sustainability; it is for this reason that the Sustainable Development Goals (SDGs) are integrated, in fact, action in one of them will affect outcomes in others. In consequence, research on the SDGs is broad, complex, and fragmented due to the great diversity of disciplines and approaches involved, making it difficult to obtain valuable and unbiased information for future studies. As a result, a comprehensive review of contributions could provide a comprehensive critical perspective. This article applies SciMAT software to analyze the evolution of this field of research through a systematic literature review of bibliographic records on the SDGs and a review based on bibliometric analysis of 10,272 selected records. Additionally, hidden themes and their development in this field from 1990 to 2020 have been identified to produce strategic diagrams, graphs of thematic evolution and performance indicators of the research field in different periods. The results obtained show a constantly evolving scientific field, from its initial focus on the millennium goals to the gradual inclusion of the current SDGs. They provide field experts with a comprehensive overview of the status quo and predict the dynamic directions of future research, serving as a basis for the development of new strategies for the implementation of the SDGs.
\end{abstract}

Keywords: analysis of science mapping; bibliometric analysis; SciMAT; sustainable development goals; systematic literature review

\section{Introduction}

In 1987, in the Brundtland Report, the United Nations (UN) defined sustainable development as "development that meets the needs of the present without compromising the ability of future generations to meet their own needs" [1]. Furthermore, it emphasizes that the three interrelated concepts of sustainable development are social sustainability, economic sustainability, and environmental sustainability; this means that each action or decision must consider natural, human, and economic capital to achieve responsible and sustainable development [2,3]. As a result, over the past decades, the concept of sustainability has attracted global attention and has been widely discussed by policy- and decision-makers, academics, and experts. In fact, sustainable development is now part of almost all political agendas in which a variety of goals and targets have been set to make the world a more sustainable and resilient place for all.

Thus, the Millennium Summit that took place on 18 September 2000, in New York City, led to the adoption of the UN Millennium Declaration, which aimed to create an international association to reduce global levels of extreme poverty. This meeting was the result of work carried out over the course of 10 years. In the declaration, the 191 UN member states and world leaders defined values as well as guiding principles and committed to seven common goals: peace, security, and disarmament; development and poverty eradication; protection of our common environment; human rights, democracy, 
and good governance; protection of vulnerable people; meet the special needs of Africa; and strengthening the UN [4]. This resolution evolved into a set of eight goals, known as the eight Millennium Development Goals (MDGs), that address various social, economic, and environmental issues.

The MDGs were an initiative developed to measure social performance based on 21 targets and 60 official indicators. They established eight targets in different dimensions of development that were intrinsically interrelated, fed back and monitored through quantifiable indicators to measure progress made. These goals constituted an international initiative for the promotion of development and the eradication of poverty that, in its conception, considered the multidimensional nature of these two concepts $[5,6]$.

The MDGs have successfully focused global attention on a broad-based development framework that has been superseded by the current Sustainable Development Goals (SDGs). Thus, on 25 September 2015, The UN General Assembly approved Resolution A/RES/70/1 on "Transforming our world: the 2030 Agenda for Sustainable Development" [7]. The agenda was agreed upon by the 193 members of the UN and outlined 17 SDGs, whose goals were to solve the economic, social, and environmental problems that hinder global progress towards sustainability [8]. The 17 SDGs with their 169 targets and 213 measurable indicators form a global action plan, with a broad scope incorporating "Five P's", namely planet, people, prosperity, peace, and partnership [9]. The SDGs are as follows: no poverty (SDG1); zero hunger (SDG 2); good health and well-being (SDG 3); quality education (SDG 4); gender equality (SDG 5); drinking water and sanitation (SDG 6); clean and affordable energy (SDG 7); decent work and economic growth (SDG 8); industry, innovation and infrastructure (SDG 9); reduction of inequality (SDG 10); sustainable cities and communities (SDG 11); responsible consumption and production (SDG 12); climate action (SDG 13); underwater life (SDG 14); life on earth (SDG 15); strong institutions for peace and justice (SDG 16); and partnerships to achieve the goals (SDG 17).

The SDGs call for global action among governments, businesses, and civil society organizations to achieve shared and sustainable prosperity [10]; they also allow the overcoming of previous partial approaches to sustainable development [11,12]. However, there are important challenges to overcome, highlighting the importance of paying more attention to the interrelationships between sectors, between actors and between countries with greater and lesser degrees of economic development [13]. In addition, there are strong interdependencies between goals, and the delay or failure to implement one goal will affect the others. Furthermore, there are concerns as to how countries will implement the goals using conventional policy that is unable to address tradeoffs between goals [14].

Consequently, due to the complexity of these interrelationships, the wide range of disciplines involved and the complex transition from the MDGs (2000-2015) to the SDGs (2015-2030), scientific research has a fundamental role to play in the success of the SDGs. Although the evolution of this discourse has been the focus of much of the academic literature [15-21], a comprehensive discursive analysis of the transition from the MDGs to the SDGs has not yet been carried out. As a result, it is impossible to get a single starting point from which to access this topic. Not having a broad vision of the research area or the evolution of problems in the field makes it difficult to obtain valuable and impartial information for future research. Therefore, comprehensive reviews are needed to facilitate the integration of these contributions and provide a critical perspective.

Bibliometric analysis provides objective criteria with which to evaluate the work done by researchers [22] and provide a macroscopic view of a large body of academic literature [23]. Alan Pritchard introduced the concept of bibliometric analysis in 1969. However, a bibliographic study in a particular field date back to the 19th century [24]. There are two main methods in bibliometric research: performance analysis and scientific mapping. While performance analysis aims to evaluate the impact of citations on the scientific production of different scientific agents, scientific mapping shows the structure of conceptual, social, and intellectual scientific research as well as its evolution and dynamic aspects. These methods provide a spatial representation of how disciplines, fields, specializations 
and individual articles or authors relate to each other [25], examining the bibliographic material from an objective and quantitative perspective [26].

Although studies have been found that apply biometric analysis in the field of SDGs research, they focus on specific disciplines. Thus, Pizzi et al. [27] systematically reviewed, through bibliometric methods and a systematic bibliographic review, scientific knowledge about the SDGs and the business sector. Prieto-Jiménez et al. [28] focused on SDG 4, quality education. Sousa Wands [29] provides a critical view of the role of plastic in the SDGs, discussing their pros and cons, outlining a future scenario based on bibliometric mapping, analysis, and recent literature. Belmonte-Ureña et al. [30] focused on the relationship between circular economy, degrowth, green growth and the SDGs. Rochon et al. [31] conducted a systematic review of the literature to provide information and lessons on how the SDGs statement can influence health financing reforms for universal health coverage based on countries' experiences.

For all the above, this article aims to analyze the existing knowledge about the SDGs and their evolution from the MDGs, using an integrated double analysis: a systematic review of the literature (SRL) and a bibliometric analysis. To meet this objective, the following specific objectives were established: (i) a quantitative analysis based on an SLR and (ii) a qualitative review based on performance analysis and scientific mapping. This study will contribute to the existing body of knowledge by highlighting and evaluating trends and patterns in SDGs research, establishing research topics, mapping researcher networks and finally recommending areas for future study.

This study will contribute to the existing body of knowledge by highlighting trends and patterns in the SDGs research field, establishing your research topics, mapping researcher networks, and recommending areas for future study.

\section{Materials and Methods}

A double analysis was performed to achieve the objectives of this study (Figure 1). This double analysis consisted of the following phases: (i) an SRL of bibliographic records on SDGs and MDGs as well as (ii) a bibliometric analysis of the identified documents. Each of these phases is described in detail in the following sections.

\subsection{Systematic Literature Review}

The SRL establishes a methodological approach that collects all the evidence-based pre-specified eligibility criteria [32]. The SRL follows a protocol that defines the search string, the strategy, the exclusion criteria, and the methods to extract data by synthesizing the results [33]. In this article, SLR is based on the guidelines in Kitchenham et al. [34] (Figure 1), which are collected in the following stages:

1. Planning and formulation of the problem. In this first stage, the research questions are defined based on the objectives set, the exclusion criteria of the relevant bibliographic records and the definition of the expected results.

2. Selection of the database(s), keywords, and search string. Bibliographic databases, keywords and search strings are identified.

3. Selection of literature. A literature search is performed, and relevant articles are selected according to the PRISMA flowchart guidelines [35]. Relevant documents are those that contain the data necessary to address the objectives of the investigation.

4. Identification of periods. Finally, periods are identified. The periods are established according to the number of relevant documents identified, the main items and the turning points of the research field. 
PHASE I SYSTEMATIC LITERATURE REVIEW (SRL)
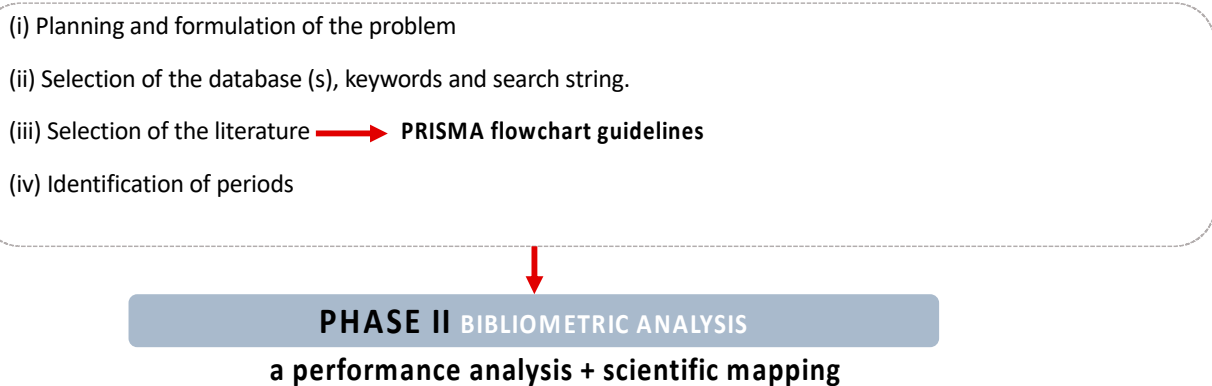

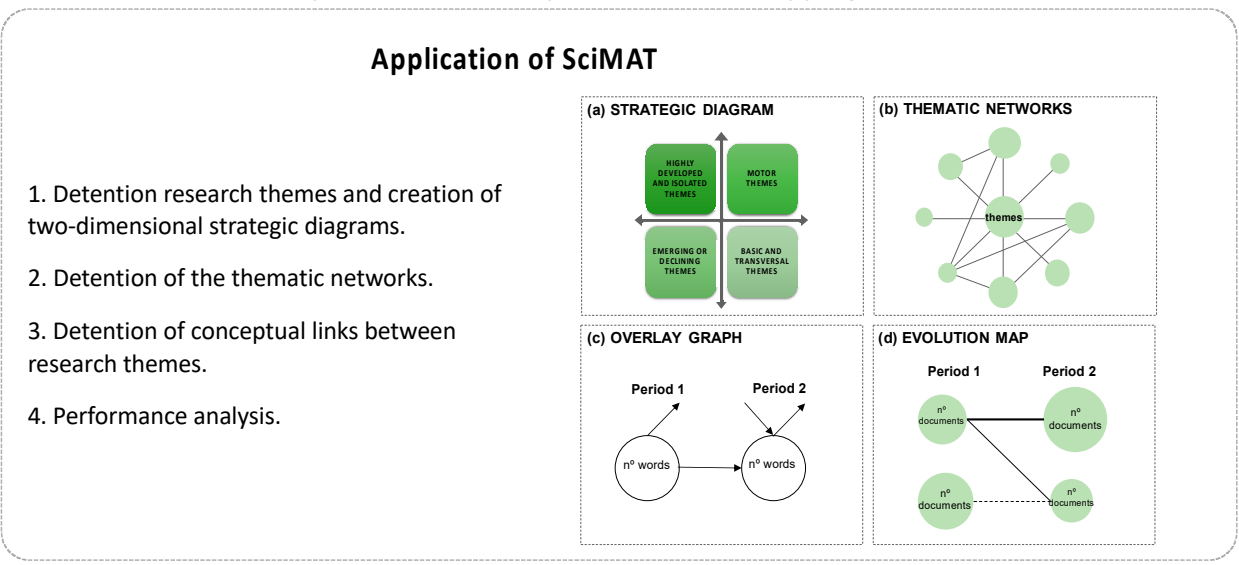

Figure 1. Materials and methods in addition to examples of a strategic diagram (a); thematic network (b); overlay graph (c); and evolution map (d).

\subsection{Bibliometric Analysis: Science Mapping and Performance Analysis}

Once the SRL has been applied, a bibliometric analysis is performed. The bibliometric analysis aims to obtain a spatial representation of the relationship between disciplines, specializations, documents, and individual authors. It is an integrated double analysis: a performance analysis and a scientific mapping. The performance analysis evaluates the impact of the citations of the scientific production and the scientific mapping shows the conceptual, social, or intellectual structure of the research as well as its evolution and dynamic aspects. In this work, SciMAT v1.1.04 (Science Mapping Analysis Software Tool) was used to perform the bibliometric analysis, referring to the research topics.

SciMAT is based on the analysis of common words [36] and the h-index [37]. The $\mathrm{h}$-index of a researcher measures the quality of their research based on the number of their articles in scientific journals and the citations received [38]. The h-index was defined by Hirsch [39] as "A scientist has an h-index if $\mathrm{h}$ of his articles $N p$ has at least $\mathrm{h}$ citations each and the other articles $(\mathrm{N} p-h)$ have $\leq \mathrm{h}$ citations each". SciMAT incorporates methods, algorithms, and measurements from all steps of the general scientific mapping workflow, from preprocessing to viewing scientific mapping results $[38,39]$. This tool establishes the stages described below.

\subsubsection{Detection Research Themes and Creation of Two-Dimensional Strategic Diagrams}

First, the tool generates the equivalence index to detect the research topics [40]. Then the software uses the single-center algorithm [41] to detect the most relevant topics. This generates a strategic diagram per set period. Diagrams are based on centrality and density [42]. Centrality is the degree of interaction of a research topic with other research topics. The density gives an idea of the level of development of that topic, measuring the internal cohesion of all the links between the keywords that describe the topic $[43,44]$. The diagrams are divided into four quadrants that capture the following four types of research topics: 
(a) Motor issues. These are in the upper right quadrant. Well-developed and important topics in the scientific field, essential for the construction of the research area. They have a strong centrality and high density.

(b) Very developed and isolated themes. These are in the upper left quadrant. Topics that are highly developed internally, but isolated from the rest of the topics. These are specialized topics in peripheral areas of the research field.

(c) Emerging or declining issues. These are in the lower left quadrant. Topics that lack development and relevance. These topics can evolve and position themselves as relevant topics or disappear. These will be reflected in the next period.

(d) Basic and transversal themes. These are in the lower right quadrant. These topics are essential to the scientific field, but they are not well developed yet.

\subsubsection{Detection of the Thematic Networks}

These graphs show the relationship of each topic of the strategy diagrams with the keywords and their interconnections. Figure $1 \mathrm{~b}$ shows an example of a thematic network. Here, several keywords are interconnected, where the size of the circle is proportional to the number of documents corresponding to each keyword, and the thickness of the link between two circles is proportional to the equivalence index.

\subsubsection{Detection of Conceptual Links between Research Themes}

Through the inclusion index, conceptual links are detected between research topics in different periods [45]. The strength of association between themes is also detected. The following two types of graphics are used for its representation:

- Overlay graphic. The horizontal arrow represents the number of words shared by both periods. The top entry arrow represents the number of new words in period 2 and the top exit arrow represents the missing words in period 2.

- Thematic map of evolution. Solid lines mean that the linked topic shares the parent. A dotted line means that the topics share elements that are not the main element. The thickness of the borders is proportional to the inclusion index and the volume of the spheres is proportional to the number of published documents.

\subsubsection{Performance Analysis}

The relative contribution of the research topic to the entire research field is measured quantitatively and qualitatively, and is used to establish the most prominent, productive and high-impact subfields using bibliometric indicators, such as the number of articles and citations published and different types of h-index.

\section{Results}

Once the steps of the previous section have been applied the results are analyzed in Figures $2-7$ and Tables $1-3$ and are discussed below.

\subsection{Systematic Literature Review}

This section presents the results obtained by applying the SLR methodology. It includes the definition of the research questions, the search process, and the definition of the PRISMA flowchart (Figure 2).

\subsubsection{Planning and Problem Formulation}

The main objective of this work is to analyze existing knowledge about the SDGs and their evolution since the MDGs. Therefore, the following research questions (RQ) were determined based on the objectives of this work:

- RQ1: What is the status of this field of study?

- RQ2: What are the key concepts that define the research field?

- RQ3: What are the most relevant issues and turning points in the field of research?

- RQ4: Towards what topics is the research field evolving? 
- RQ5: What are the limitations of the current research?

- RQ6: What are the most influential works in the field of research?

- RQ7: Who are the most prolific authors in the research field?

- RQ8: What are the most relevant countries and organizations in the field of research?

\subsubsection{Selection of the Database(s), Keywords, and the Search String}

Regarding the selection of databases, in this study the Web of Science (WoS) and SCOPUS databases were selected. These databases have many high-impact international scientific and technical publications from all disciplines.

In terms of keywords, this review has addressed the evolution of the SDGs, which have their origin in the MDGs. Therefore, the keywords must cover both topics. Two search strings were used, one for each database. Thus, for SCOPUS, the search performed was TITLE-ABS-KEY ("SUSTAINABLE DEVELOPMENT GOALS") OR TITLE-ABS-KEY ("MILLENNIUM DEVELOPMENT GOALS"). For the WoS, the search was THEME: ("SUSTAINABLE DEVELOPMENT GOALS”) OR THEME: (“MILLENNIUM DEVELOPMENT GOALS"). The searches in the databases were carried out on 30 May 2021.

\subsubsection{Selection of the Literature}

Once the keywords and search strings were identified, the records obtained were collected and archived. Next, the PRISMA flowchart guide (Figure 2) was applied, which shows the number of relevant documents identified.

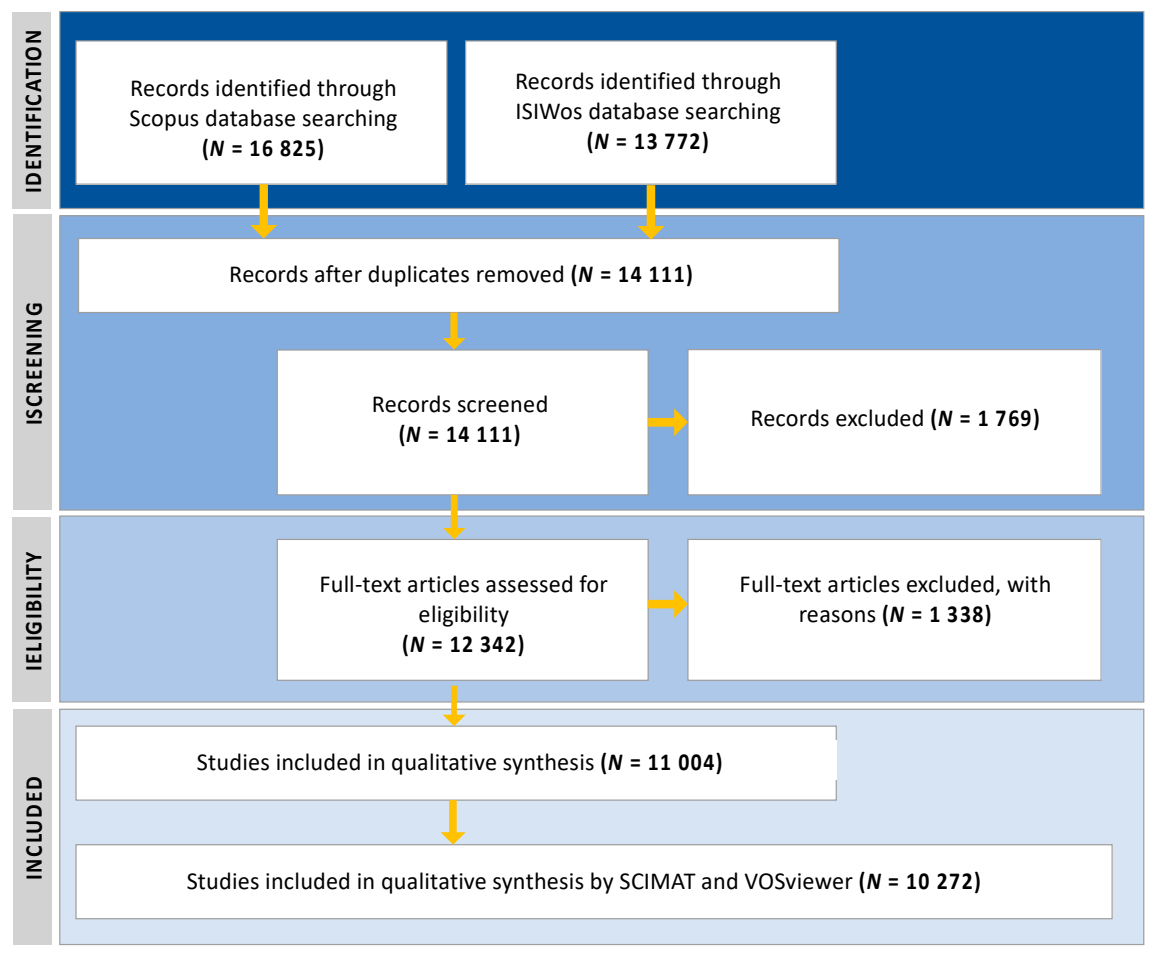

Figure 2. PRISMA flowchart.

A total of 30,597 bibliographic records were retrieved from the two selected databases. After eliminating 16,487 duplicates, 1769 of the remaining 14,111 records were excluded, applying the exclusion criteria (only article-type documents, full documents, and documents in English). The remaining 12,342 records were then screened for title, abstract and keywords, and an additional 1338 records were excluded because they did not cover the topics included in this review. Finally, after a final exclusion phase, 10,272 relevant documents were selected for the study. 


\subsubsection{Identification of Periods}

The identification of the periods was determined from the main milestones and turning points in the evolution of the SDGs and MDGs. The time horizon used was from 1990 to 2020, since the inclusion in the scientific literature of the fundamental issues from which the SDGs are derived took place in the 1990s. It was then subdivided into the following three periods, considering the number of selected papers, as well as the relevant milestones, to analyze trends in publication patterns:

- First period (1990-2010): 1171. The first records selected date from the 90s, where the foundations were laid for the introduction of the MDGs. In 1992, the Program of Action-Agenda 21 was a clear milestone in this period. In September 2000, leaders from 189 countries met at the United Nations headquarters to sign the Millennium Declaration, a landmark document that they committed to achieving by 2015 .

- Second period (2010-2015): 2148. A relevant milestone that started this period is the Summit on the Millennium Development Goals. With only 5 years to go until 2015, the deadline for achieving the MDGs, the United Nations Secretary-General, Ban Ki-moon, has convened a summit to accelerate progress towards these goals.

- Third period (2016-2020): 6953. The last period begins with the establishment of the 17 SDGs. The SDGs coincided with another landmark agreement in 2015, the Paris Agreement approved at the Conference on Climate Change (COP21). Together with the Sendai Framework for Disaster Risk Reduction, signed in Japan in March 2015 , these agreements provide a set of common standards and achievable targets for reducing carbon emissions, managing the risks of climate change in addition to natural disasters and rebuilding after a crisis.

Figure 3 shows the distribution of 10,272 publications per year. As can be seen, up to 2000 the number of documents was low. In 2010 there is a significant increase in interest in this field of research. Since 2015, the year in which the 2030 Agenda for Sustainable Development was debated at the Rio +20 Conference, there has been a significant increase in the number of publications. Most of the articles in this systematic review were published between 2016 and 2020, which is a clear indication of growing research interest, and the projection of this analysis indicates that this number will continue to increase.

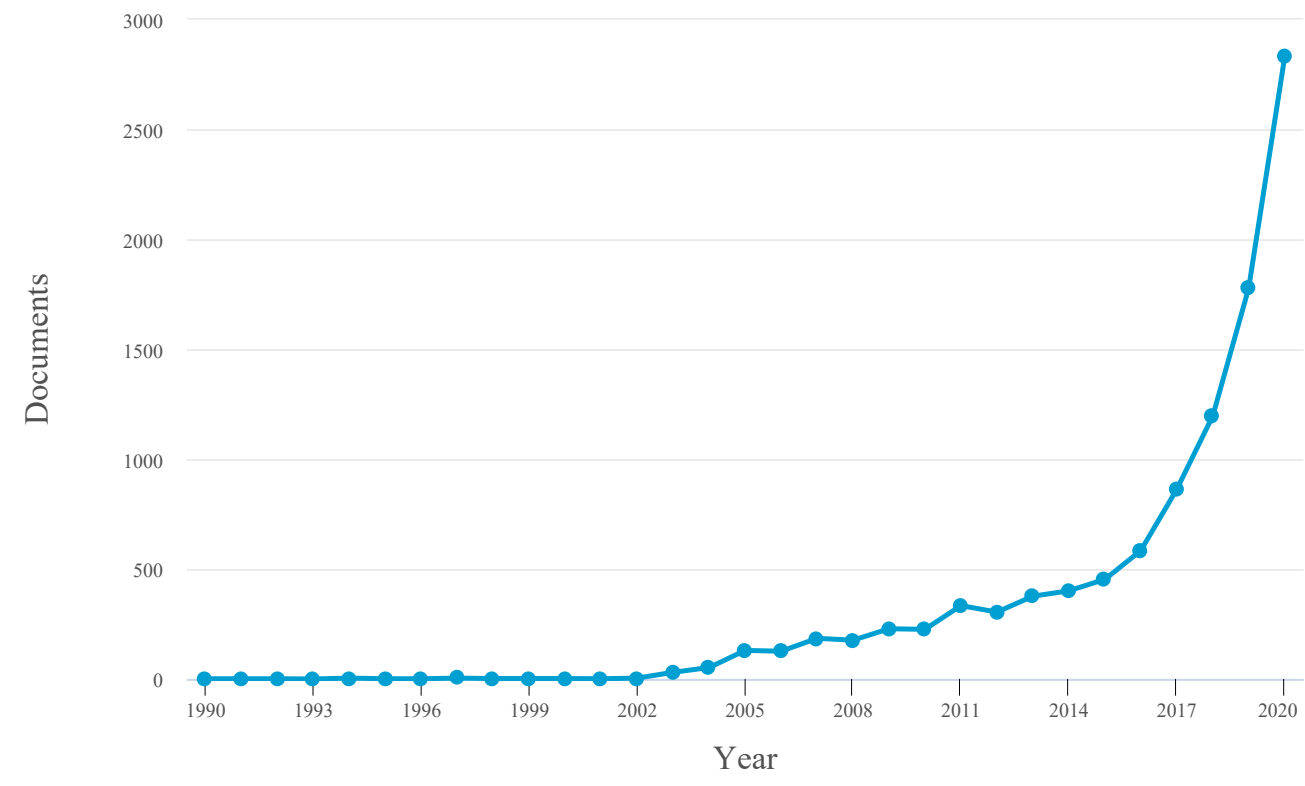

Figure 3. Documents per year. 


\subsection{Bibliometric Analysis: Science Mapping and Performance Analysis}

In this section, the following graphs are analyzed and discussed: strategic diagrams, one for each period; thematic networks of relevant topics; and an overlay chart and thematic evolution map. In addition, the most cited documents and publications are analyzed.

\subsubsection{Strategic Diagrams}

Three strategic diagrams (shown in Figure 4) were generated to analyze the changes over time in the research field for the three periods considered (1990-2010, 2011-2015 and 2016-2020). Table 1 shows the performance measures obtained for each topic in terms of several documents, h-index and values of centrality and density. Below is an analysis of the results obtained for each period.

- First period (1990-2010). According to the strategic diagram presented in Figure 4a, 12 research topics are observed in the 1171 selected works in this period. Of these, five are driving themes (rural area, human, Millennium Development Goals, young adult, and health care facility, three are emerging or in decline (human rights, water resource and practice guideline), two are highly developed and isolated (United Nations and environmental policy) and two are considered basic and cross-cutting issues (economics and government). The performance analysis of each topic, from Table 1, complements the information provided by the diagram. The topics with the highest performance measures are human, health care facility, economics, and government. These topics have more than 25,000 citations between them, obtaining a higher h-index than the rest of the topics.

- Second period (2011-2015). According to the strategic diagram presented in Figure $4 b$, 16 themes are observed in the 2148 works selected in this period. Six of these issues were driving issues (HIV infections, financial management, rural area, Millennium Development Goals, health policy and human), four were emerging or declining themes (environment, United Nations, climate change and statistical model), three were highly developed and isolated themes (mobile phone, household survey and non-communicable disease) and three were basic and cross-cutting themes (retrospective study, trends and health care system). According to the performance measures (Table 1), the following three themes can be highlighted: human, health policy and cross-sectional study. These research topics had a high h-index and were considered in the largest number of documents.

- Third period (2016-2020). According to the strategic scheme presented in Figure 4c, nine research topics are observed in the 6953 works selected in this period. Seven were driving themes (greenhouse gases, disability-adjusted life year, health care cost, maternal health service, Sustainable Development Goals, human and health policy), six were emerging or declining themes (health risk, innovation, environmental impact assessment, prospective study, investment, innovation, and water resource) and two were basic topics (household and retrospective study). According to the performance measures (Table 1), the topics Sustainable Development Goals, human and health policy can be highlighted. These research topics had a high impact and had a higher h-index than the other topics. 
(a) Period 1 (1990 - 2010)

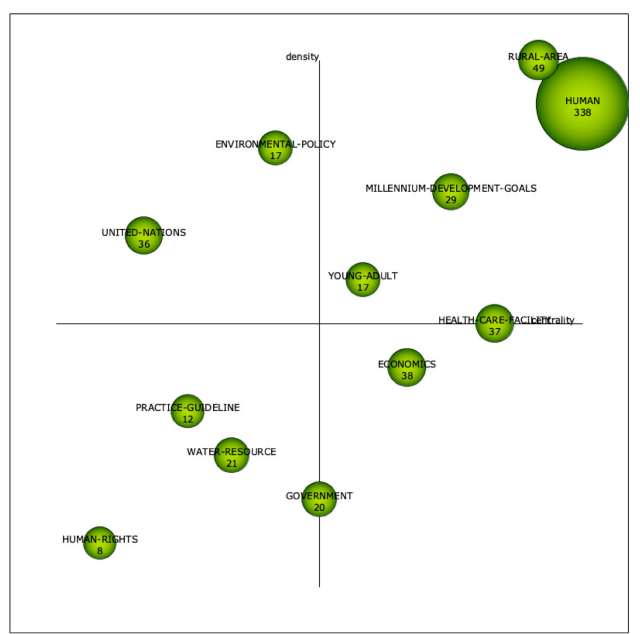

(c) Period 3 (2016 - 2020)

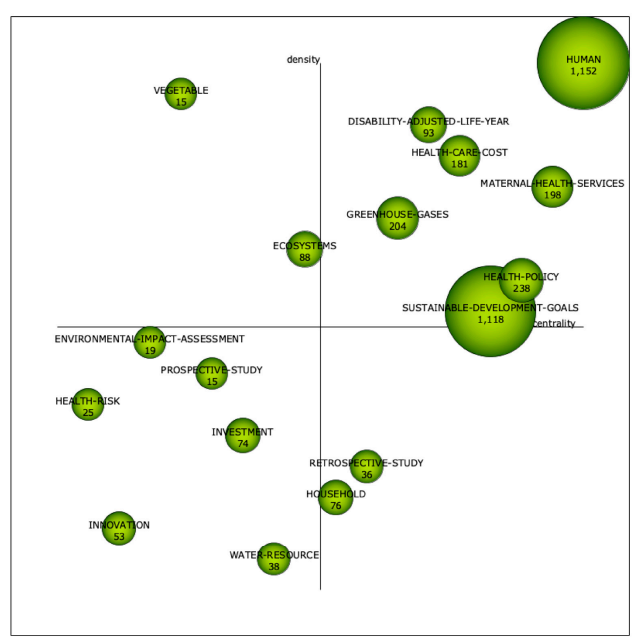

(b) Period 2 (2011 - 2015)
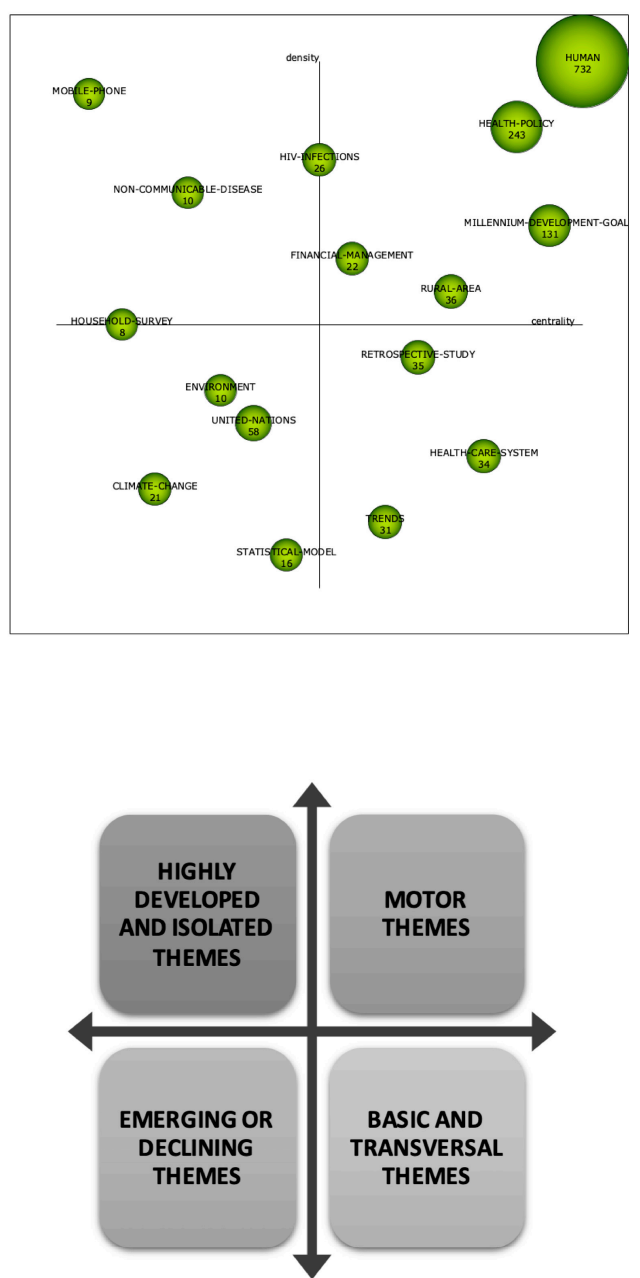

Figure 4. Strategic diagrams for (a) period 1, (b) period 2 and (c) period 3.

LOW-INCQME-POPULATION

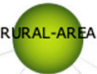

INVESTMENT

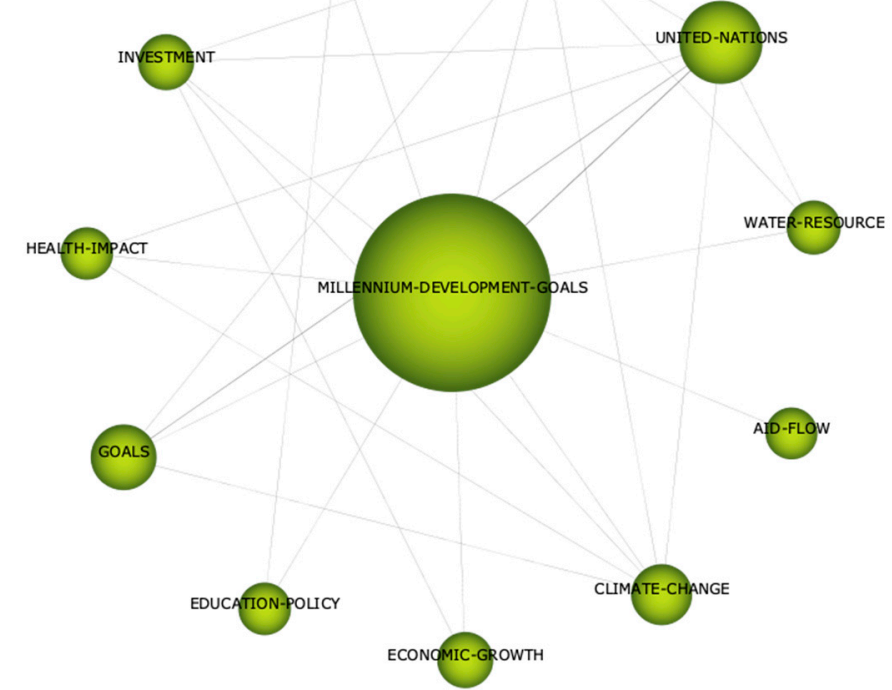

Figure 5. Thematic network for period 2. 
Table 1. Performance measures of the themes.

\begin{tabular}{|c|c|c|c|c|c|}
\hline Journals & $\begin{array}{c}\mathrm{N}^{\mathrm{o}} \\
\text { Documents }\end{array}$ & $\begin{array}{c}\mathrm{N}^{\mathrm{o}} \\
\text { Citations }\end{array}$ & h-Index & Centrality & Density \\
\hline \multicolumn{6}{|l|}{ Period 1 (1990-2010) } \\
\hline HUMAN & 338 & 19,647 & 71 & 135.4 & 35.38 \\
\hline $\begin{array}{l}\text { ENVIRONMENTAL- } \\
\text { POLICY }\end{array}$ & 17 & 391 & 9 & 24.37 & 27.04 \\
\hline $\begin{array}{c}\text { MILLENNIUM- } \\
\text { DEVELOPMENT-GOALS }\end{array}$ & 29 & 851 & 17 & 40.97 & 9.22 \\
\hline RURAL-AREA & 49 & 1777 & 25 & 52.88 & 41.43 \\
\hline HEALTH-CARE-FACILITY & 37 & 2131 & 24 & 43.3 & 5.68 \\
\hline ECONOMICS & 38 & 1583 & 19 & 35.86 & 3.13 \\
\hline UNITED-NATIONS & 36 & 899 & 14 & 15.59 & 7.02 \\
\hline WATER-RESOURCE & 21 & 766 & 11 & 20 & 2.65 \\
\hline GOVERNMENT & 20 & 1413 & 14 & 26.52 & 2.14 \\
\hline YOUNG-ADULT & 17 & 916 & 11 & 35.57 & 6.22 \\
\hline PRACTICE-GUIDELINE & 12 & 622 & 10 & 19.41 & 2.73 \\
\hline HUMAN-RIGHTS & 8 & 106 & 4 & 5.53 & 0.87 \\
\hline \multicolumn{6}{|l|}{ Period 2 (2011-2015) } \\
\hline HUMAN & 732 & 25.98 & 60 & 167.09 & 53.16 \\
\hline HEALTH-POLICY & 243 & 5679 & 38 & 74.76 & 15.38 \\
\hline $\begin{array}{c}\text { MILLENNIUM- } \\
\text { DEVELOPMENT-GOALS }\end{array}$ & 131 & 4474 & 3. 4 & 79.33 & 7.11 \\
\hline CLIMATE-CHANGE & 21 & 923 & 13 & 6.61 & 2.77 \\
\hline HEALTH-CARE-SYSTEM & 3. 4 & 621 & 15 & 42.28 & 2.97 \\
\hline HIV-INFECTIONS & 26 & 490 & 14 & 23.73 & 12.05 \\
\hline RURAL-AREA & 36 & 894 & 16 & 34.45 & 5.24 \\
\hline TRENDS & 31 & 625 & 13 & 29.72 & 1.79 \\
\hline UNITED-NATIONS & 58 & 1284 & 17 & 19.33 & 3.09 \\
\hline RETROSPECTIVE-STUDY & 35 & 512 & 13 & 33.71 & 3.88 \\
\hline $\begin{array}{l}\text { FINANCIAL- } \\
\text { MANAGEMENT }\end{array}$ & 22 & 260 & 9 & 29.46 & 6.97 \\
\hline STATISTICAL-MODEL & 16 & 1262 & 11 & 22.45 & 1.61 \\
\hline HOUSEHOLD-SURVEY & 8 & 170 & 6 & 6.45 & 4.26 \\
\hline ENVIRONMENT & 10 & 173 & 7 & 14.12 & 3.12 \\
\hline MOBILE-PHONE & 9 & 408 & 8 & 2.92 & 23.65 \\
\hline $\begin{array}{l}\text { NON-COMMUNICABLE- } \\
\text { DISEASE }\end{array}$ & 10 & 517 & 9 & 8.66 & 8.44 \\
\hline \multicolumn{6}{|l|}{ Period 3 (2016-2020) } \\
\hline HUMAN & 1152 & 18,115 & 52 & 133.63 & 45.04 \\
\hline $\begin{array}{l}\text { MATERNAL-HEALTH- } \\
\text { SERVICES }\end{array}$ & 198 & 2503 & 22 & 42.76 & 8.66 \\
\hline $\begin{array}{l}\text { DISABILITY-ADJUSTED- } \\
\text { LIFE-YEAR }\end{array}$ & 93 & 6239 & 2. 3 & 29.69 & 14.06 \\
\hline GREENHOUSE-GASES & 204 & 4143 & 30 & 20.61 & 6.37 \\
\hline $\begin{array}{c}\text { SUSTAINABLE- } \\
\text { DEVELOPMENT-GOALS }\end{array}$ & 1118 & 12,263 & 47 & 34.35 & 2.94 \\
\hline HEALTH-POLICY & 238 & 4535 & 26 & 42.35 & 3.15 \\
\hline HEALTH-CARE-COST & 181 & 2908 & 26 & 29.92 & 9.43 \\
\hline ECOSYSTEMS & 88 & 1494 & 19 & 13.83 & 4.62 \\
\hline RETROSPECTIVE-STUDY & 36 & 271 & 9 & 20.11 & 1.29 \\
\hline HOUSEHOLD & 76 & 742 & 15 & 19.17 & 1.27 \\
\hline INVESTMENT & 74 & 1787 & 19 & 10.81 & 2 \\
\hline WATER-RESOURCE & 38 & 621 & 15 & 11.24 & 0.81 \\
\hline INNOVATION & 53 & 628 & 15 & 5.13 & 1.22 \\
\hline HEALTH-RISK & 25 & 205 & 9 & 4.41 & 2 \\
\hline VEGETABLE & 15 & 312 & 9 & 6.33 & 22.87 \\
\hline PROSPECTIVE-STUDY & 15 & 163 & 6 & 8.2 & 2.57 \\
\hline $\begin{array}{l}\text { ENVIRONMENTAL- } \\
\text { IMPACT-ASSESSMENT }\end{array}$ & 19 & 257 & 9 & 6.28 & 2.79 \\
\hline
\end{tabular}

\subsubsection{Thematic Networks}

In this section, to further explore relevant themes and future trends, three thematic networks, one per period, were selected based on their saliency, which captures developed, basic and emerging research over time. The interconnections between the themes (circles) are represented in Figure 5. The circle size indicates the number of documents, and the 
thickness of the line corresponds to the strength of the correlation between the two nodes. An analysis of the results obtained for each period is shown below.

In Figure 5, we can see that the Millennium Development Goals topic is closely linked to other essential topics such as low-income population, rural area, United Nations, water resource, aid flow, climate change, economic growth, education policy and health impact, among others. Thus, in the years that preceded the introduction of the SDGs, the international development agenda focused on the economic performance of countries. The MDGs incorporated a greater focus on economic development. However, it was believed that such development would be achieved mainly through the global eradication of extreme poverty [45-47]. The MDGs and their founding document, the Millennium Declaration, focused on reducing economic poverty without a clear focus on other dimensions of development such as human rights, empowerment, and equality [48]. Therefore, poverty reduction was framed primarily as something that could be addressed through economic rather than social or political reforms $[49,50]$.

On the other hand, as seen in Figure 6, the SDG issue is related to issues such as stakeholder, United Nations, economic growth, human rights, integrated approach, and policy implementation, among others. This shows that the SDGs differ in several key elements compared to the MDGs. The SDGs expanded the goal of the MDGs, that is, the reduction of extreme poverty, to include four dimensions: inclusive social development, inclusive economic development, environmental sustainability and peace and security. The SDGs take a much more comprehensive approach to sustainable development than the MDGs. They offer a more people-centered development agenda. In general, the SDGs present a much more integrated approach to sustainable development than the MDGs [51-53]. Unlike the MDGs that focused on developing countries, the SDGs apply to all development challenges regardless of country. Developing and developed countries are all responsible for sustainable development through the implementation of the SDGs [54].

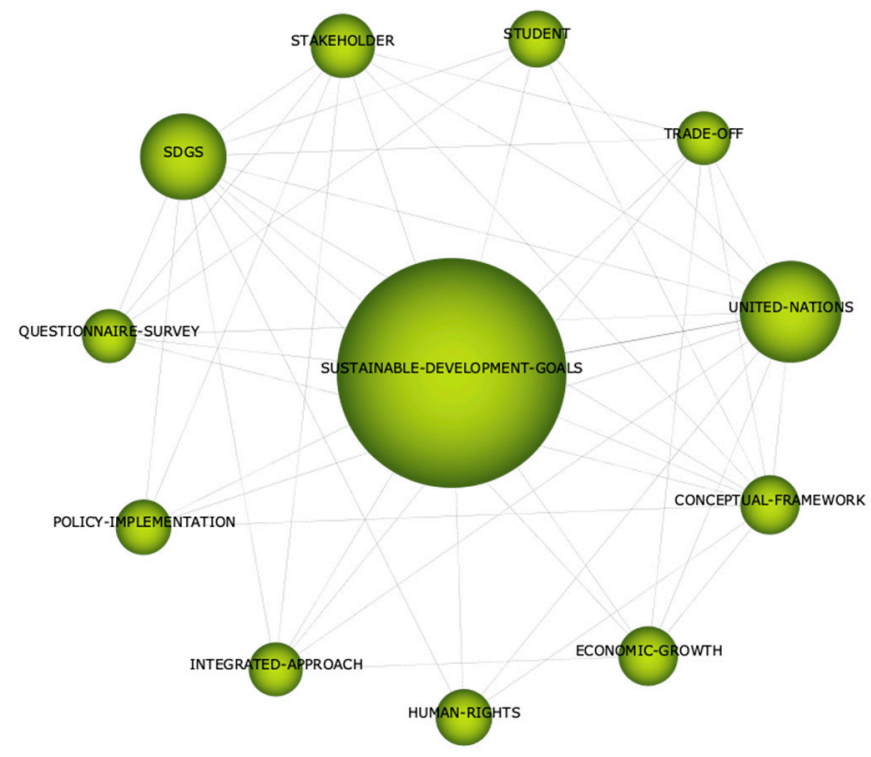

Figure 6. Thematic networks by period 3 .

\subsubsection{Overlay Graph and Thematic Evolution Map}

Finally, to analyze the evolution of the topics over time, Figure 7a,b represents the number of keywords per period and their evolution, the number of incoming and outgoing keywords in addition to the number and percent of keywords that are used. They persist from one period to the next. As seen in Figure $7 \mathrm{a}$, the number of keywords grows over the periods, in parallel with the increase in the number of documents over the years. The number of keywords increases from 209 to 1625 between the first and the last period, a growth rate of $123 \%$. Specifically, of the 209 keywords that appeared in the first period, $93 \%$ 
(195) remain in the second period, and 837 new words are added, for a total of 1032 words. Finally, in the third period, 965 (94\%) keywords remain from the second period and 730 new keywords appear, resulting in a total of 1696. These results indicate that the number of new and transitional keywords is high, but also that the number of keywords shared for successive periods has increased. Therefore, the growing thematic diversity of the MDGs and SDGs research field and the fact that keywords reappear with greater force in the following periods could be indicators that this research field is gradually consolidating, but also that the number of shared keywords has increased for successive periods. Therefore, the growing thematic diversity of the MDGs and SDGs research field as well as the fact that keywords reappear with greater force in the following periods could be indicators that this research field is gradually consolidating but also that the number of shared keywords has increased for successive periods. Therefore, the growing thematic diversity of the MDG and SDG research field and the fact that keywords reappear with greater force in the following periods could be indicators that this research field is gradually consolidating.

\subsubsection{Performance Analysis}

The 10,272 documents analyzed received 24,591 citations. Table 2 shows the five publications with the highest number of citations, a total of 3052, which represents $12 \%$ of the total. The most-cited documents focus on different aspects of the thematic field analyzed, revealing its diversity. These papers deal with the goals, indicators, values, and practice of sustainable development; soil science and how the discipline is related to land has important links to several of the SDGs, which are demonstrated through the functions of soils and the ecosystem services that are linked to those functions [55-58]. Additionally, analyzing progress on specific topics towards MDGs four and five started in 2010 with additional surveys, censuses, vital records, and verbal autopsy data [56]. Furthermore, for the third Millennium Development Goal (MDG), on gender equality and the empowerment of women, exploring the concept of women's empowerment and highlighting the indicators associated with this goal (education, employment, and political participation) can contribute to it [57].

In this study, 2663 journals were identified. Table 3 shows the publications of $18.01 \%$ of the analyzed documents, which are arranged in descending order according to the number of documents. Most are research journals that focus on human-environmental, cultural, economic, and social sustainability, cleaner production practices and development studies.

Finally, Figure $7 \mathrm{~b}$ shows the thematic evolution of the research field through the analysis of the origins and interrelationships of the themes. The thickness of the lines represents the strength of the association as measured by the inclusion index. If the graph is analyzed from the point of view of the number of documents, the environmental policy theme of the first period evolved into the climate change, rural area, and household survey themes for the second period. For the first period, it is worth highlighting the economics theme, which evolved into the human, health policy, HIV infections and statistical model themes. 
(a) Overlay graph

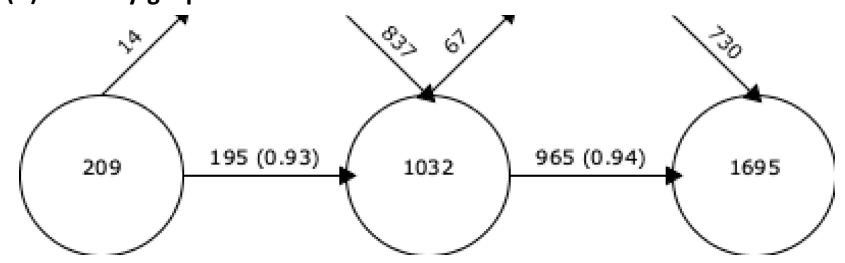

(b) Thematic evolution map

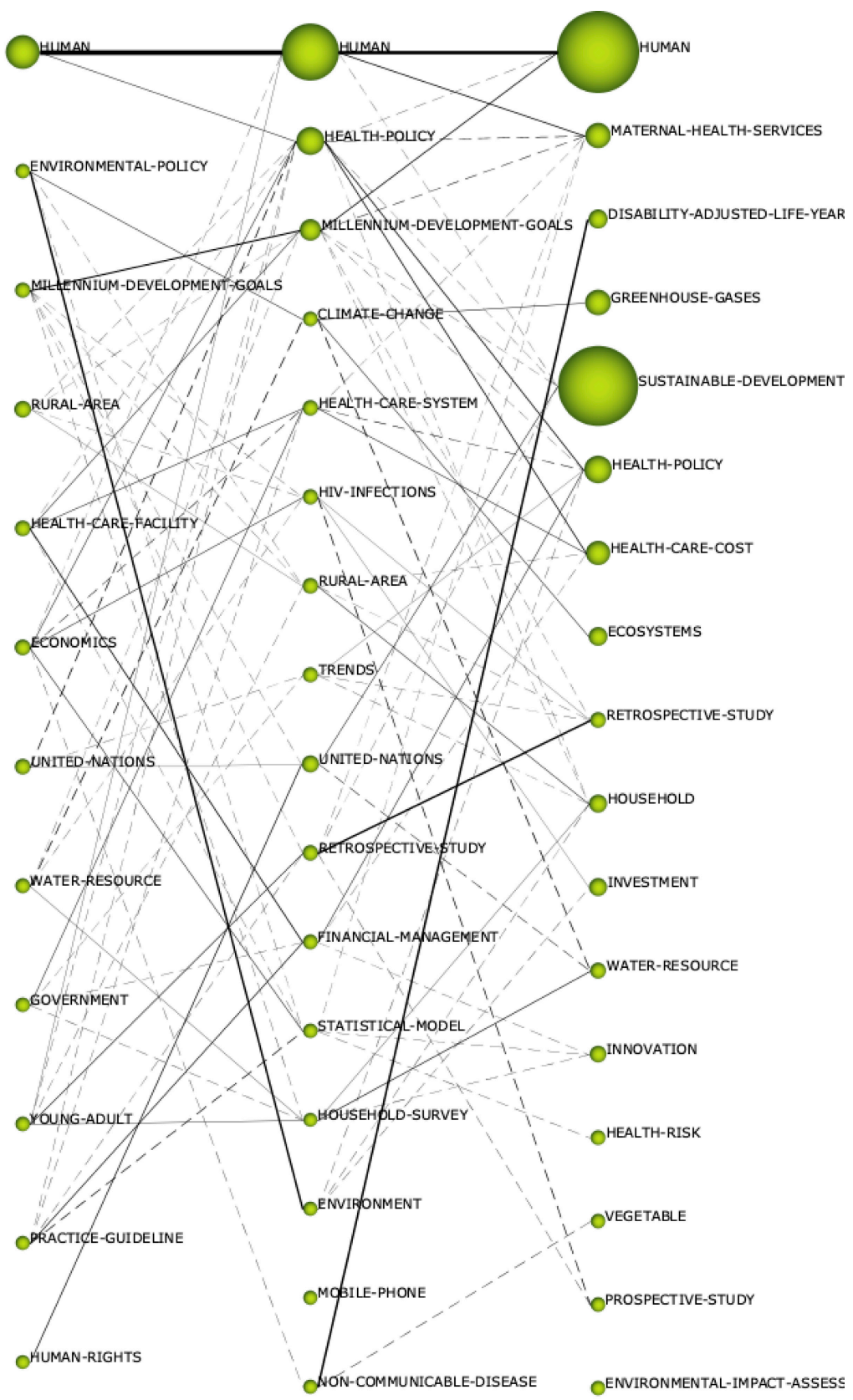

Figure 7. (a) Overlay graph and (b) thematic evolution map. 
Table 2. Most-cited documents.

\begin{tabular}{|c|c|c|c|c|}
\hline Document & Author & Year & $\mathrm{N}^{\circ}$ Appointments & References \\
\hline $\begin{array}{l}\text { What is sustainable } \\
\text { development? Goals, indicators, } \\
\text { values, and practice }\end{array}$ & $\begin{array}{l}\text { Kates, R.W., Parris, T.M. and } \\
\text { Leiserowitz, A.A. }\end{array}$ & 2012 & 2314 & [58] \\
\hline $\begin{array}{l}\text { The significance of soils and soil } \\
\text { science towards the realization } \\
\text { of the United Nations } \\
\text { sustainable development goals }\end{array}$ & $\begin{array}{l}\text { Bouma, J., Montanarella, L., } \\
\text { Keesstra, S.D., Wallinga, J., } \\
\text { Tittonell, P., Smith, P., Cerdà, A., } \\
\text { Quinton, J.N., Pachepsky, Y., Van } \\
\text { Der Putten, W.H., Bardgett, R.D., } \\
\text { Moolenaar, S., Mol, G., Jansen, B. } \\
\text { and Fresco, L.O. }\end{array}$ & 2005 & 699 & [55] \\
\hline $\begin{array}{l}\text { Progress towards Millennium } \\
\text { Development Goals } 4 \text { and } 5 \text { on } \\
\text { maternal and child mortality: An } \\
\text { updated systematic analysis }\end{array}$ & $\begin{array}{l}\text { Murray, C.J.L., Naghavi, M., } \\
\text { Dwyer-Lindgren, L., Wang, H., } \\
\text { Foreman, K.J., Lopez, A.D., } \\
\text { Lozano, R., Rajaratnam, J.K., } \\
\text { Marcus, J.R., Lofgren, K.T., } \\
\text { Phillips, D. and Atkinson, C. }\end{array}$ & 2016 & 610 & [56] \\
\hline $\begin{array}{l}\text { Gender equality and women's } \\
\text { empowerment: A critical } \\
\text { analysis of the third Millennium } \\
\text { Development Goal }\end{array}$ & Kabeer, N. & 2011 & 603 & [57] \\
\hline $\begin{array}{l}\text { Overcoming health-systems } \\
\text { constraints to achieve the } \\
\text { Millennium Development Goals }\end{array}$ & $\begin{array}{c}\text { Evans, T., Hyder, A.A., Bennett, S., } \\
\text { Travis, P., Haines, P.A., Pang, T., } \\
\text { Bhutta, P.Z., Pielemeier, N.R. and } \\
\text { Mills, P.A. }\end{array}$ & 2005 & 576 & [59] \\
\hline
\end{tabular}

Table 3. Main journal contributing to the research field.

\begin{tabular}{ccc}
\hline Journals & $\begin{array}{c}\mathbf{N}^{\mathbf{o}} \text { Documents Citation } \\
\text { Index }\end{array}$ & $\begin{array}{c}\mathbf{N}^{\mathbf{0}} \text { of Citation Indexes of the } \\
\text { Journal }\end{array}$ \\
\hline Sustainability (Switzerland) & 873 & 8796 \\
PLoS ONE & 208 & 4567 \\
Journal of Cleaner Production & 208 & 1279 \\
World Development & 123 & 1204 \\
Science of the Total & 114 & 702 \\
Environment & & \\
\hline
\end{tabular}

\section{Discussion}

As can be seen from the results, the MDGs were revolutionary because they offered a common discourse to reach a global agreement. The eight objectives were realistic, easy to communicate and had a clear mechanism for quantifying and monitoring them. The progress made on the MDGs was substantial. When the Millennium Development Goals (MDGs) were established in 2000, many authors argued that their goals were so ambitious that they could not be achieved. Within this framework of achievements and progress came the Sustainable Development Goals (SDGs) and the 2030 Agenda, a new roadmap that represents an opportunity to incorporate the lessons learned in the previous process and reach children who, for various reasons, have been left out of progress and development, and focus on building a sustainable world in which environmental sustainability, social inclusion and economic development are equally valued.

By 2015, the world was already consistent in reducing the world rates of extreme poverty and hunger by half, and with the arrival of the SDGs the momentum generated by the MDGs continued within a global development framework that had people as its central axis. Therefore, organizations, citizens, scientists, academics, and representatives of the private sector from all over the world were protagonists in the process of developing 
the new program: a framework document that will govern the activities for the well-being of people and the care of the planet for the next 15 years.

The discussions that have taken place since the launch of the SDGs tend to focus on how society can contribute to achieving these goals. However, it is often very easily taken for granted that society is already convinced that they should do so.

\section{Conclusions}

This article offered a comprehensive discursive analysis of the transition from the MDGs to the SDGs, which until now has only been partially done. The literature review shows that discourses around sustainable development have evolved with the transition from the MDGs to the SDGs. The SDGs have benefited from both the successes and the shortcomings of the MDGs. The MDGs have had their share of weaknesses, which have been recognized to improve the performance of the SDGs.

Thus, the Millennium Development Goals (MDGs) mark a historic and effective method of global mobilization to achieve a set of important social priorities throughout the world. They express widespread public concern about poverty, hunger, disease, gender inequality and environmental degradation. The MDGs help promote global awareness, political responsibility, improved metrics, social feedback, and public pressure.

Developing countries have made substantial progress towards achieving the MDGs, although progress varies widely across targets, countries, and regions. Furthermore, for more than a decade, the MDGs have remained at the center of global policy debates and national policy planning. They have been incorporated into the work of non-governmental organizations and civil society in general and are taught to students at all levels of education.

Furthermore, there is a general feeling among policymakers and civil society that progress against poverty, hunger and disease is remarkable, and that the MDGs have played an important role in ensuring that progress. In a world already suffering from dangerous climate change and other serious environmental ills, there is also a widespread understanding that global environmental goals need a higher profile alongside poverty reduction goals.

On the other hand, the evolution towards the SDGs finally helps to take the world onto a sustainable path. The results show how the SDGs have rapidly gained ground due to the growing urgency of sustainable development for the whole world. These show a combination of economic development, environmental sustainability, and social inclusion. Certainly, thus far, no consensus has been reached on trade-offs and synergies between economic, environmental, and social objectives. Still, a shared focus on economic, environmental, and social goals is a hallmark of sustainable development and represents a broad consensus on which the world can build.

Author Contributions: Conceptualization, C.D.-L. and C.M.-B.; methodology, C.D.-L. and J.J.D.1.T.B.; software, C.D.-L. and J.J.D.1.T.B.; formal analysis, C.D.-L.; writing-original draft preparation, C.D.-L. and B.R.-R.; writing-review and editing, M.Z.; supervision, M.Z.; project administration, M.Z.; funding acquisition, M.Z. All authors have read and agreed to the published version of the manuscript.

Funding: This research was funded by FEDER/Junta de Andalucía-Consejería de Economía y Conocimiento, thanks to the project "Design of strategists to face the impact of COVID-19 on the compliance with the SDGs in Andalusia", reference number CV20-01172.

Institutional Review Board Statement: Not applicable.

Informed Consent Statement: Not applicable.

Data Availability Statement: Not applicable.

Acknowledgments: This research was supported by the research group TEP-968 Tecnologías para la Economía Circular (Technologies for Circular Economy) of the University of Granada.

Conflicts of Interest: The authors declare no conflict of interest. The funders had no role in the design of the study; in the collection, analyses, or interpretation of data; in the writing of the manuscript; or in the decision to publish the results. 


\section{References}

1. World Commission on Environment and Development. Our Common Future; Oxford University Press: London, UK, 1987.

2. Halkos, G.; Gkampoura, E.C. Where Do We Stand on the 17 Sustainable Development Goals? An Overview on Progress. Econ. Anal. Policy 2021, 70, 94-122. [CrossRef]

3. Purvis, B.; Mao, Y.; Robinson, D. Three Pillars of Sustainability: In Search of Conceptual Origins. Sustain. Sci. 2019, 14, 681-695. [CrossRef]

4. United Nations. United Nations Millennium Declaration; United Nations: New York, NY, USA, 2000.

5. Sessa, M. Measuring and Monitoring the Achievements of the Millennium Development Goals through Dynamic Composite Indices. Soc. Indic. Res. 2016, 127, 469-503. [CrossRef]

6. Vandemoortele, J. The MDG Story: Intention Denied. Dev. Chang. 2011, 42, 1-21. [CrossRef]

7. United Nations. Transforming Our World: The 2030 Agenda for Sustainable Development Transforming Our World: The 2030 Agenda for Sustainable Development Preamble. 2020. Available online: https://sdgs.un.org/2030agenda (accessed on 4 August 2021).

8. Gue, I.H.V.; Ubando, A.T.; Tseng, M.L.; Tan, R.R. Artificial Neural Networks for Sustainable Development: A Critical Review. Clean Technol. Environ. Policy 2020, 22, 1449-1465. [CrossRef]

9. UN General Assembly. Draft Outcome Document of the United Nations Summit for the Adoption of the Post-2015 Development Agenda; UN General Assembly: New York, NY, USA, 2015.

10. Khaled, R.; Ali, H.; Mohamed, E.K.A. The Sustainable Development Goals and Corporate Sustainability Performance: Mapping, Extent and Determinants. J. Clean. Prod. 2021, 311, 127599. [CrossRef]

11. Jones, P.; Comfort, D.; Hillier, D. Common Ground: The Sustainable Development Goals and the Marketing and Advertising Industry. J. Public Aff. 2018, 18, e1619. [CrossRef]

12. Fuso Nerini, F.; Tomei, J.; To, L.S.; Bisaga, I.; Parikh, P.; Black, M.; Borrion, A.; Spataru, C.; Castán Broto, V.; Anandarajah, G.; et al. Mapping Synergies and Trade-Offs between Energy and the Sustainable Development Goals. Nat. Energy 2018, 3, 10-15. [CrossRef]

13. Stafford-Smith, M.; Griggs, D.; Gaffney, O.; Ullah, F.; Reyers, B.; Kanie, N.; Stigson, B.; Shrivastava, P.; Leach, M.; O'Connell, D. Integration: The Key to Implementing the Sustainable Development Goals. Sustain. Sci. 2017, 12, 911-919. [CrossRef]

14. Stoknes, P.E. How to Achieve the Sustainable Development Goals within Planetary Boundaries by 2050. Real-World Econ. Rev. $2019,87,230$.

15. Arts, K. Inclusive Sustainable Development: A Human Rights Perspective. Curr. Opin. Environ. Sustain. 2017, $24,58-62$. [CrossRef]

16. Fasoulis, I. Governing the Oceans: A Study into Norway's Ocean Governance Regime in the Wake of United Nations Sustainable Development Goals. Reg. Stud. Mar. Sci. 2021, 101983. [CrossRef]

17. Holden, E.; Linnerud, K.; Banister, D. Sustainable Development: Our Common Future Revisited. Glob. Environ. Chang. 2014, 26, 130-139. [CrossRef]

18. Sneddon, C.; Howarth, R.B.; Norgaard, R.B. Sustainable Development in a Post-Brundtland World. Ecol. Econ. 2006, 57, 253-268. [CrossRef]

19. Gresh, A.; Dallman, E.; Johnson, E.; Mena-Carrasco, F.; Rosales, L.; Pantaleon, V.; Brooks, K.; Sharps, P. Fostering Future Global Nurse Leaders to Work toward Meeting Millennium Development Goals (MDGs) and Sustainable Development Goals (SDGs): A Global Health Intern Program at Johns Hopkins University School of Nursing. Ann. Global Health 2016, 82, 388. [CrossRef]

20. Redclift, M. Sustainable Development (1987-2005): An Oxymoron Comes of Age. Sustain. Dev. 2005, 13, 212-227. [CrossRef]

21. Lélé, S.M. Sustainable Development: A Critical Review. World Dev. 1991, 19, 607-621. [CrossRef]

22. Noyons, E.C.M.; Moed, H.F.; Luwel, M. Combining Mapping and Citation Analysis for Evaluative Bibliometric Purposes: A Bibliometric Study. J. Am. Soc. Inf. Sci. 1999, 50, 115-131. [CrossRef]

23. Van Nunen, K.; Li, J.; Reniers, G.; Ponnet, K. Bibliometric Analysis of Safety Culture Research. Saf. Sci. 2018, 108, 248-258. [CrossRef]

24. Osareh, F. Bibliometrics, Citation Analysis and Co-Citation Analysis: A Review of Literature, I. Libri 1996, 46, 149-158. [CrossRef]

25. Small, H. Visualizing Science by Citation Mapping. J. Am. Soc. Inf. Sci. 1999, 50, 799-813. [CrossRef]

26. Albort-Morant, G.; Ribeiro-Soriano, D. A Bibliometric Analysis of International Impact of Business Incubators. J. Bus. Res. 2016, 69, 1775-1779. [CrossRef]

27. Pizzi, S.; Caputo, A.; Corvino, A.; Venturelli, A. Management Research and the UN Sustainable Development Goals (SDGs): A Bibliometric Investigation and Systematic Review. J. Clean. Prod. 2020, 276, 124033. [CrossRef]

28. Prieto-Jiménez, E.; López-Catalán, L.; López-Catalán, B.; Domínguez-Fernández, G. Sustainable Development Goals and Education: A Bibliometric Mapping Analysis. Sustainability 2021, 13, 2126. [CrossRef]

29. De Sousa, F.D.B. The Role of Plastic Concerning the Sustainable Development Goals: The Literature Point of View. Clean. Responsible Consum. 2021, 3, 100020. [CrossRef]

30. Belmonte-Ureña, L.J.; Plaza-Úbeda, J.A.; Vazquez-Brust, D.; Yakovleva, N. Circular Economy, Degrowth and Green Growth as Pathways for Research on Sustainable Development Goals: A Global Analysis and Future Agenda. Ecol. Econ. 2021, 185, 107050. [CrossRef]

31. Odoch, W.D.; Senkubuge, F.; Hongoro, C. How Has Sustainable Development Goals Declaration Influenced Health Financing Reforms for Universal Health Coverage at the Country Level? A Scoping Review of Literature. Glob. Health 2021, 17. [CrossRef] 
32. Dawarka, V.; Bekaroo, G. Building and Evaluating Cloud Robotic Systems: A Systematic Review. Robot. Comput.-Integr. Manuf. 2021, 73, 102240. [CrossRef]

33. Martínez-Aires, M.D.; López-Alonso, M.; Martínez-Rojas, M. Building Information Modeling and Safety Management: A Systematic Review. Saf. Sci. 2018, 101, 11-18. [CrossRef]

34. Kitchenham, B.; Charters, S. Procedures for Performing Systematic Literature Reviews in Software Engineering; Keele University \& Durham University: Newcastle, UK, 2007.

35. Liberati, A.; Altman, D.G.; Tetzlaff, J.; Mulrow, C.; Gøtzsche, P.C.; Ioannidis, J.P.A.; Clarke, M.; Devereaux, P.J.; Kleijnen, J.; Moher, D. The PRISMA Statement for Reporting Systematic Reviews and Meta-Analyses of Studies That Evaluate Healthcare Interventions: Explanation and Elaboration. BMJ Clin. Res. Ed. 2009, 339, b2700. [CrossRef]

36. Callon, M.; Courtial, J.-P.; Turner, W.A.; Bauin, S. From Translations to Problematic Networks: An Introduction to Co-Word Analysis. Soc. Sci. Inf. 1983, 22, 191-235. [CrossRef]

37. Hirsch, J.E. An Index to Quantify an Individual's Scientific Research Output. Proc. Natl. Acad. Sci. USA 2005, 102, 16569-16572. [CrossRef] [PubMed]

38. Oakleaf, M. Writing Information Literacy Assessment Plans: A Guide to Best Practice. Commun. Inf. Lit. 2009, 3, 80-90. [CrossRef]

39. Cobo, M.J.; López-Herrera, A.G.; Herrera-Viedma, E.; Herrera, F. An Approach for Detecting, Quantifying, and Visualizing the Evolution of a Research Field: A Practical Application to the Fuzzy Sets Theory Field. J. Informetr. 2011, 5, 146-166. [CrossRef]

40. López-Robles, J.R.; Rodríguez-Salvador, M.; Gamboa-Rosales, N.K.; Ramirez-Rosales, S.; Cobo, M.J. The Last Five Years of Big Data Research in Economics, Econometrics and Finance: Identification and Conceptual Analysis. Procedia Comput. Sci. 2019, 162, 729-736. [CrossRef]

41. Coulter, N.; Monarch, I.; Konda, S. Software Engineering as Seen through Its Research Literature: A Study in Co-Word Analysis. J. Am. Soc. Inf. Sci. 1998, 49, 1206-1223. [CrossRef]

42. Callon, M.; Courtial, J.P.; Laville, F. Co-Word Analysis as a Tool for Describing the Network of Interactions between Basic and Technological Research: The Case of Polymer Chemsitry. Scientometrics 1991, 22, 155-205. [CrossRef]

43. Martínez, M.A.; Cobo, M.J.; Herrera, M.; Herrera-Viedma, E. Analyzing the Scientific Evolution of Social Work Using Science Mapping. Res. Soc. Work. Pract. 2015, 25, 257-277. [CrossRef]

44. Fernández-González, J.M.; Díaz-López, C.; Martín-Pascual, J.; Zamorano, M. Recycling Organic Fraction of Municipal Solid Waste: Systematic Literature Review and Bibliometric Analysis of Research Trends. Sustainability 2020, 12, 4798. [CrossRef]

45. Alcaide-Muñoz, L.; Rodríguez-Bolívar, M.P.; Cobo, M.J.; Herrera-Viedma, E. Analysing the Scientific Evolution of E-Government Using a Science Mapping Approach. Gov. Inf. Q. 2017, 34, 545-555. [CrossRef]

46. Antrobus, P. Gender Equality in the New Millennium: Goal or Gimmick? Caribb. Q. 2006, 52, 39-50. [CrossRef]

47. Fukuda-Parr, S. From the Millennium Development Goals to the Sustainable Development Goals: Shifts in Purpose, Concept, and Politics of Global Goal Setting for Development. Gend. Dev. 2016, 24, 43-52. [CrossRef]

48. Freistein, K.; Mahlert, B. The Potential for Tackling Inequality in the Sustainable Development Goals. Third World Q. 2016, 37, 2139-2155. [CrossRef]

49. Briant Carant, J. Unheard Voices: A Critical Discourse Analysis of the Millennium Development Goals' Evolution into the Sustainable Development Goals. Third World Q. 2017, 38, 16-41. [CrossRef]

50. Amin, S. The Millennium Development Goals: A Critique from the South. Mon. Rev. 2006, 57, 1-15. [CrossRef]

51. Marks, S.P. The Human Rights Framework for Development: Seven Approaches. Reflect. Right Dev. 2005, 23-60. [CrossRef]

52. Campbell, D.A. An Update on the United Nations Millennium Development Goals. J. Obstet. Gynecol. Neonatal Nurs. 2017, 46, e48-e55. [CrossRef]

53. Fedderke, J.; Klitgaard, R. How Much Do Rights Matter? World Dev. 2013, 51, 187-206. [CrossRef]

54. Liverman, D.M. Geographic Perspectives on Development Goals: Constructive Engagements and Critical Perspectives on the MDGs and the SDGs. Dialogues Hum. Geogr. 2018, 8, 168-185. [CrossRef]

55. Keesstra, S.D.; Bouma, J.; Wallinga, J.; Tittonell, P.; Smith, P.; Cerdà, A.; Montanarella, L.; Quinton, J.N.; Pachepsky, Y.; van der Putten, W.H.; et al. The Significance of Soils and Soil Science towards Realization of the United Nations Sustainable Development Goals. Soil 2016, 2, 111-128. [CrossRef]

56. Lozano, R.; Wang, H.; Foreman, K.J.; Rajaratnam, J.K.; Naghavi, M.; Marcus, J.R.; Dwyer-Lindgren, L.; Lofgren, K.T.; Phillips, D.; Atkinson, C.; et al. Progress towards Millennium Development Goals 4 and 5 on Maternal and Child Mortality: An Updated Systematic Analysis. Lancet 2011, 378, 1139-1165. [CrossRef]

57. Kabeer, N. Gender Equality and Women's Empowerment: A Critical Analysis of the Third Millennium Development Goal 1. Gend. Dev. 2010, 13, 13-24. [CrossRef]

58. Robert, K.W.; Parris, T.M.; Leiserowitz, A.A. What Is Sustainable Development? Goals, Indicators, Values, and Practice. Environ. Sci. Policy Sustain. Dev. 2012, 47, 8-21. [CrossRef]

59. Travis, P.; Bennett, S.; Haines, A.; Pang, T.; Bhutta, Z.; Hyder, A.A.; Pielemeier, N.R.; Mills, A.; Evans, T. Overcoming HealthSystems Constraints to Achieve the Millennium Development Goals. Lancet 2004, 364, 900-906. [CrossRef] 